\title{
Effect of acute alterations in inspired oxygen tension on methacholine induced bronchoconstriction in patients with asthma
}

\author{
Kenneth D Dagg, Lorna J Thomson, Robert A Clayton, Scott G Ramsay, \\ Neil C Thomson
}

\begin{abstract}
Background - Recent in vitro and in vivo studies in animals have suggested that ambient oxygen tension may influence airway responsiveness to bronchoconstrictor stimuli. These observations may have relevance to the management of acute exacerbations of asthma. The present studies were designed to examine the influence of inspired oxygen tension $\left(\mathrm{FiO}_{2} 1.0,0.21\right.$, $0.15)$ on methacholine induced bronchoconstriction in patients with asthma.

Methods - In a dual study two groups of asthmatic patients performed methacholine inhalation challenges breathing either air $\left(\mathrm{FiO}_{2} \mathbf{0 . 2 1}\right)$ or a hypoxic gas mixture $\left(\mathrm{FiO}_{2} 0.15\right)$ in study 1 and air $\left(\mathrm{FiO}_{2}\right.$ $0.21)$ or hyperoxia $\left(\mathrm{FiO}_{2} 1.0\right)$ in study 2 . The gases were administered through a closed breathing circuit in a randomised double blind fashion. The $\mathbf{P C}_{20}$ values (dose of methacholine causing a $20 \%$ fall in forced expiratory volume in one second $\left(F_{1} V_{1}\right)$ ) were calculated after each methacholine challenge by linear interpolation from the logarithmic dose response curve. Plasma catecholamine levels were measured before and after methacholine challenges as well as heart rate, oxygen saturation, and percentage end tidal carbon dioxide levels.

Results - The geometric mean $\mathbf{P C} \mathrm{C}_{20}$ value for methacholine was significantly lower on the hypoxic study day than on the normoxic day in study 1 (mean difference in $\mathbf{P C}_{20}$ values $2.88 \mathrm{mg} / \mathrm{ml}$ (95\% CI 1.4 to 5.3); $\mathbf{p}<0.05)$, but there was no significant difference in the geometric mean $\mathbf{P C}_{20}$ value for methacholine between the hyperoxic and normoxic study days in study 2 (mean difference in $\mathbf{P C}_{20}$ values $1.45 \mathrm{mg}$ / $\mathrm{ml}(95 \%$ CI 0.83 to 2.51$)$ ).
\end{abstract}

Conclusions - Acute hypoxia potentiates methacholine induced bronchoconstriction and acute hyperoxia has no effect in

Table 1 Patient characteristics

\begin{tabular}{|c|c|c|c|c|c|}
\hline & \multirow{2}{*}{$\begin{array}{l}\text { No. of } \\
\text { patients }\end{array}$} & \multirow{2}{*}{$\begin{array}{l}\text { Mean }(S D) \\
\text { age (years) }\end{array}$} & \multicolumn{2}{|c|}{ Mean $(S D) F E V_{1}$} & \multirow{2}{*}{$\begin{array}{l}\text { Geometric mean (range) } \\
P C_{20} \text { methacholine }(\mathrm{mg} / \mathrm{ml})\end{array}$} \\
\hline & & & Litres & $\%$ predicted & \\
\hline $\begin{array}{l}\text { Study } 1 \\
\text { Study } 2\end{array}$ & $\begin{array}{l}11 \\
14\end{array}$ & $\begin{array}{l}42(12) \\
36(9.2)\end{array}$ & $\begin{array}{l}2.76(0.49) \\
2.80(0.60)\end{array}$ & $\begin{array}{l}86(7.7) \\
90(8.6)\end{array}$ & $\begin{array}{l}1.13(0.04-7.90) \\
0.84(0.04-7.90)\end{array}$ \\
\hline
\end{tabular}

$\mathrm{FEV}_{1}=$ forced expiratory volume in one second; $\mathrm{PC}_{20}$ methacholine = concentration of methacholine provoking a fall in $\mathrm{FEV}_{1}$ of $20 \%$. mild to moderate patients with stable asthma.

(Thorax 1997;52:453-457)

Keywords: hyperoxia, hypoxia, bronchoconstriction, methacholine, asthma.

Little is known about the effect of acute alterations in oxygen tension on the responsiveness of the airways to bronchoconstrictor stimuli. Recent in vitro and in vivo studies in animals suggest that hypoxia potentiates and hyperoxia attenuates the airway constrictor response to certain stimuli. ${ }^{12}$ Similar in vivo studies in man, however, have produced conflicting findings. ${ }^{3-5}$ If airway responsiveness is increased by a fall in oxygen tension during acute exacerbations of asthma, then the administration of high concentrations of inspired oxygen may act to reduce this effect.

The present studies were designed to investigate the effect of acute hypoxia and hyperoxia on methacholine induced bronchoconstriction in patients with asthma.

\section{Methods \\ PATIENTS \\ Study 1}

Eleven mild asthmatic patients (five men) of mean (SD) age 42 (12) years were recruited into the study (table 1). All were receiving inhaled $\beta_{2}$ agonists as required, 10 were receiving regular inhaled corticosteroids, two were taking regular inhaled salmeterol, and one a long acting oral theophylline.

\section{Study 2}

Fourteen adult mild asthmatic patients (five men) of mean (SD) age 36 (9.2) years were recruited into the study (table 1). All were taking inhaled $\beta_{2}$ agonists on an as required basis, 10 were receiving regular inhaled corticosteroids, two were taking regular oral theophyllines, and one inhaled salmeterol.

In both studies on each study day inhaled $\beta_{2}$ agonists were discontinued for eight hours, salmeterol for 24 hours, and oral theophyllines for 48 hours prior to attendance. Patients were asked to continue their inhaled corticosteroids as usual. They were asked to refrain from caffeine containing products for eight hours before each study day. All patients had been 
stable for a period of two months before entry into the study with no significant change in their asthma symptoms or medication. All patients gave informed consent to the studies which had the approval of the West ethics committee.

STUDY DESIGN

For both study 1 and study 2 patients attended the laboratory on three separate days at approximately the same time each day. Patients were excluded from the study if there was any significant change in their asthma symptoms or medication between visits. The maximum period between each visit was seven days. During the initial screening visit each patient underwent a methacholine inhalation challenge test to determine the $\mathrm{PC}_{20}$ - that is, the concentration of methacholine causing a $20 \%$ fall in forced expiratory volume in one second $\left(\mathrm{FEV}_{1}\right)$. On the subsequent two days, after 30 minutes of supine rest, the patients were commenced on a closed breathing circuit. Following a 10 minute run-in period breathing air $\left(\mathrm{FiO}_{2}\right.$ 0.21) baseline measurements of $\mathrm{FEV}_{1}$, respiratory rate $(\mathrm{RR})$, heart rate (HR), oxygen saturation $\left(\mathrm{SaO}_{2} \%\right)$, inspired oxygen and carbon dioxide levels (insp $\mathrm{O}_{2} \%$, insp $\mathrm{CO}_{2} \%$ ), and expired oxygen and carbon dioxide levels $\left(\mathrm{PeTO}_{2} \%\right.$, $\left.\mathrm{PETCO}_{2} \%\right)$ were made. Venous blood was also taken for assay of plasma catecholamines.

In study 1 patients then received either air $\left(\mathrm{FiO}_{2} \quad 0.21\right)$ or a hypoxic gas mixture $\left(\mathrm{FiO}_{2}\right.$ $0.15)$ and in study 2 either air $\left(\mathrm{FiO}_{2} 0.21\right)$ or oxygen $\left(\mathrm{FiO}_{2} 1.0\right)$ for the remainder of the study day. All gases were administered in a randomised double blind manner by a second person obscured from the vision of both the patient and the doctor administering the methacholine challenge. The methacholine inhalation challenge was performed 10 minutes after starting the study gas. All measurements, except venous blood sampling, were repeated before commencing the methacholine inhalation challenge. The study day was terminated when a $P_{20}$ value had been obtained and the measurements made at baseline repeated.

\section{MEASUREMENTS}

Heart rate, oxygen saturation, inspired and expired oxygen and carbon dioxide levels

Heart rate and oxygen saturation were measured using a pulse oximetry probe (Datex Division of Instrumentarium Corp, Helsinki, Finland). A side port on the face mask allowed continuous sampling of the inspired and expired gases and monitoring of respiratory rate. The gases were analysed using an OSCARoxy TM multigas monitor (Datex Instrumentarium Corp, Helsinki, Finland). Recordings were made every 10 seconds for one minute and automatically printed by a Hewlett Packard Think Jet printer in a blind fashion. Results were analysed after completion of the study.
$F E V_{1}$

$\mathrm{FEV}_{1}$ was measured using a dry wedge spirometer (Vitalograph S, Vitalograph, Buckingham, UK) and the best of three attempts was taken for analysis.

Methacholine inhalation challenge

Baseline $\mathrm{FEV}_{1}$ was measured by taking the best of three recordings. Thereafter a saline inhalation was administered and then doubling doses of nebulised methacholine (acetyl- $\beta$ methylcholine chloride (Sigma Chemical Company, Dorset UK) made up in normal saline) were administered at five minute intervals. Each concentration was given for two minutes via a MicroCirrus nebuliser. All challenge tests were performed by the same person throughout both studies. The nebuliser output for both gases in study 1 at a flow rate of $71 / \mathrm{min}$ was $0.13 \mathrm{ml} / \mathrm{min}$, and in study 2 at a flow rate of $6 \mathrm{l} / \mathrm{min}$ the nebuliser output was $0.12 \mathrm{ml} / \mathrm{min}$ for both gases. The $\mathrm{FEV}_{1}$ was measured at 0.5 , 1.5 , and three minutes after each inhalation until a fall in $\mathrm{FEV}_{1}$ of at least $20 \%$ was achieved as determined by linear interpolation from the logarithmic dose-response curve. This result was then expressed as the methacholine $\mathrm{PC}_{20}$. All methacholine solutions were made up by the sterile unit of our pharmacy department.

Oxygen breathing circuit

All gases were administered from J size cylinders (3200 litre capacity, British Oxygen Corporation Medical Gases) via a calibrated flow head and a five litre rebreathing bag. The rebreathing bag was connected to an aircraft face mask (Thomas Respiratory Systems, London) via elephant tubing and a two way breathing valve.

\section{Plasma catecholamines}

Five millilitre aliquots of venous blood were collected into lithium heparin tubes, stored on ice, and spun within 90 minutes. Adrenaline and noradrenaline were later measured by radioenzymatic assay ${ }^{6}$ with both interassay and intra-assay variations of less than $10 \%$.

STATISTICAL ANALYSIS

Statistical analysis was performed on an Apple Mackintosh LC II computer using a Statview software package (Brainpower Inc, Calabasas). Data were analysed for treatment, period and order effects as a two period crossover clinical trial using the method described by Hills and Armitage. ${ }^{7}$ The $\mathrm{PC}_{20}$ values were logarithmically transformed before analysis. A p value of $<0.05$ was accepted as significant.

\section{Results}

There were no significant differences in baseline measurements between study days in either study (table 2). Analysis for period and order effects showed no significant differences for any measurements. 
Table 2 Mean (SE) baseline respiratory rate, heart rate and plasma catecholamine levels for patients in study 1 (hypoxia versus normoxia, $n=11$ ) and study 2 (hyperoxia versus normoxia, $n=14$ )

\begin{tabular}{|c|c|c|c|c|}
\hline \multirow[t]{2}{*}{ Baseline measurement } & \multicolumn{2}{|l|}{ Study 1} & \multicolumn{2}{|l|}{ Study 2} \\
\hline & $\begin{array}{l}\text { Normoxia } \\
\text { study day }\end{array}$ & $\begin{array}{l}\text { Hypoxia } \\
\text { study day }\end{array}$ & $\begin{array}{l}\text { Normoxia } \\
\text { study day }\end{array}$ & $\begin{array}{l}\text { Hyperoxia } \\
\text { study day }\end{array}$ \\
\hline $\mathrm{FEV}_{1}(1)$ & $2.67(0.14)$ & $2.63(0.16)$ & $2.71(0.14)$ & $2.71(0.17)$ \\
\hline Heart rate (beats/min) & $71.0(4.0)$ & $71.0(4.7)$ & $77.0(4.3)$ & $75.0(3.7)$ \\
\hline Respiratory rate (breaths $/ \mathrm{min}$ ) & $15.0(1.5)$ & $16.0(1.6)$ & $14.0(1.4)$ & $16.0(1.3)$ \\
\hline Oxygen saturation (\%) & $96.5(0.2)$ & $96.3(0.2)$ & $96.5(0.3)$ & $96.7(0.4)$ \\
\hline Inspired $\mathrm{O}_{2}(\%)$ & $20.8(0.2)$ & $21.0(0.0)$ & $21.0(0.0)$ & $20.9(0.1)$ \\
\hline End tidal $\mathrm{CO}_{2}(\%)$ & $4.66(0.11)$ & $4.64(0.14)$ & $4.49(0.17)$ & $4.47(0.21)$ \\
\hline Plasma noradrenaline $(\mathrm{nmol} / \mathrm{l})$ & $1.72(0.14)$ & $1.61(0.29)$ & $2.14(0.58)$ & $1.80(0.26)$ \\
\hline Plasma adrenaline $(\mathrm{nmol} / \mathrm{l})$ & $0.10(0.02)$ & $0.10(0.02)$ & $0.11(0.02)$ & $0.07(0.02)$ \\
\hline
\end{tabular}

$\mathrm{FEV}_{1}=$ forced expiratory volume in one second

No significant differences were found between study days in either study.

STUDY 1

Methacholine $P C_{20}$ values

The geometric mean $\mathrm{PC}_{20}$ methacholine value was significantly lower $(p<0.05)$ on the hypoxic study day than on the normoxic day (fig $1 \mathrm{~A}$ ) with a mean difference between the hypoxic and normoxic study days of $2.88 \mathrm{mg} / \mathrm{ml}(95 \%$ CI 1.40 to 5.3 ).

Oxygen saturation

Oxygen saturation was significantly lower $(\mathrm{p}<0.01)$ following hypoxia (mean $(\mathrm{SE}) \mathrm{SaO}_{2} \%$ at baseline $96.3(0.24) \%$, pre-methacholine $91.0(0.56) \%$, post-methacholine $90.5(1.0) \%)$ than following normoxia (mean (SE) $\mathrm{SaO}_{2} \%$ at baseline $96.5(0.16) \%$, pre-methacholine 96.3 (0.27)\%, post-methacholine 96.0 (0.43)\%; fig $2 \mathrm{~A})$.

\section{Heart rate}

There was no significant difference in heart rate when the hypoxia and normoxia study days were compared at any time point (data not shown).

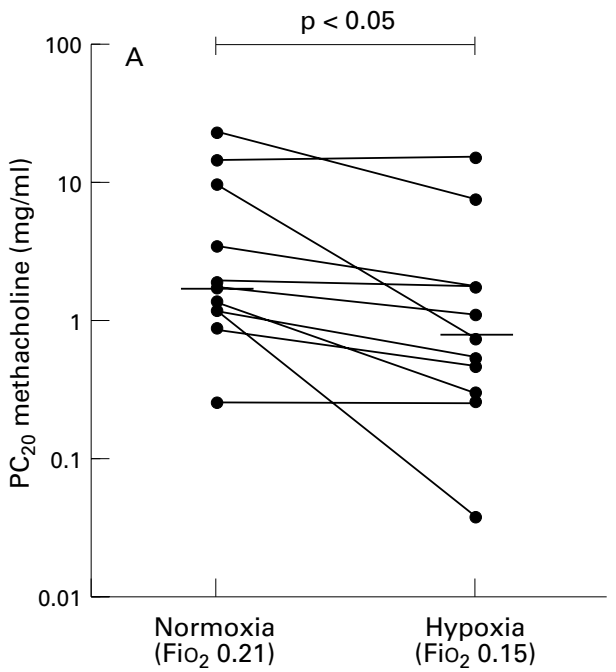

$F E V_{1}$

The mean $\mathrm{FEV}_{1}$ after 10 minutes breathing the hypoxic gas mixture alone prior to inhalation of methacholine was not significantly different from on the normoxic study day (mean (SE) $2.40(0.15) 1$ following hypoxia and $2.38(0.14)$ 1 on the normoxic study day).

STUDY 2

Methacholine $P C_{20}$ values

There was no significant difference in the geometric mean $\mathrm{PC}_{20}$ methacholine values between the normoxic and hyperoxic study days (fig 1B), the mean difference being $1.45 \mathrm{mg} / \mathrm{ml}$ (95\% CI 0.83 to 2.51 ).

\section{Oxygen saturation}

Oxygen saturation was significantly higher $(\mathrm{p}<0.01)$ following hyperoxia (mean (SE) $\mathrm{SaO}_{2} \%$ at baseline $96.7(0.35) \%$, pre-methacholine $98.1(0.23) \%$, post-methacholine 98.1 $(0.20) \%)$ than during the normoxic study day (mean (SE) $\mathrm{SaO}_{2} \%$ at baseline $96.5(0.33) \%$, pre-methacholine $96.7(0.37) \%$, post-methacholine 96.0 (0.52)\%; fig 2B).

\section{Heart rate}

The heart rate was significantly lower $(\mathrm{p}<0.05)$ on the hyperoxic study day both before and after the methacholine inhalation test than on the normoxic study day. The mean (SE) heart rate on the hyperoxic study day was: baseline 75 (4) bpm, pre-methacholine 71 (4) bpm, post-methacholine 71 (4) bpm and on the normoxic study day: baseline 77 (4) bpm, premethacholine 75 (5) bpm, post-methacholine 77 (4) bpm.

There were no significant differences in respiratory rate, percentage end tidal carbon di-

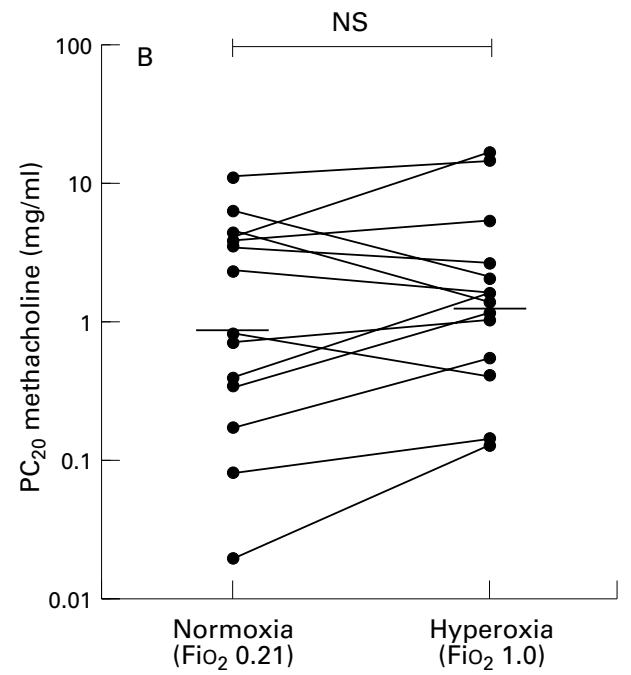

Figure 1 Effect of $(A)$ hypoxia and normoxia $(n=11)$ and $(B)$ hyperoxia and normoxia $(n=14)$ on $P C_{20}$ methacholine values in patients with asthma. 

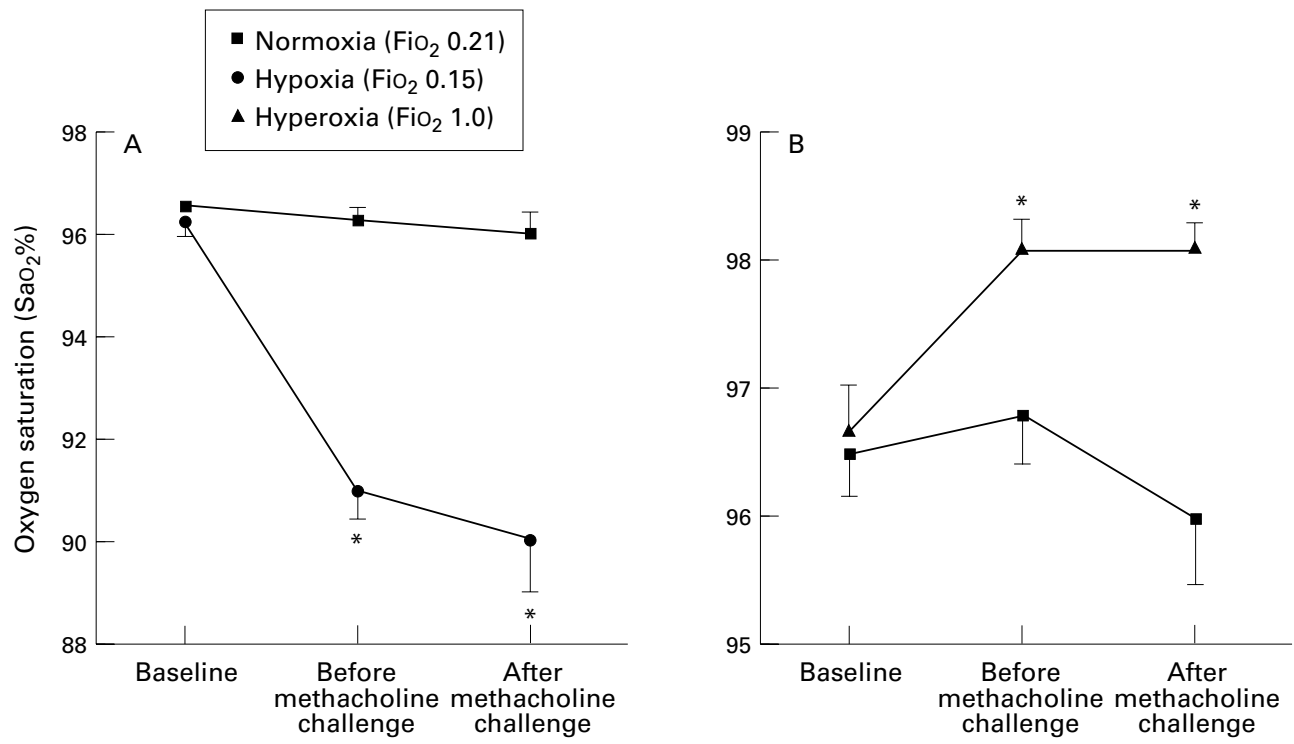

Figure 2 Effect of $(A)$ hypoxia and normoxia $(n=11)$ and $(B)$ hyperoxia and normoxia $(n=14)$ on oxygen saturation in patients with asthma. ${ }^{*} p<0.01$.

Table 3 Mean (SE) respiratory rate, end tidal carbon dioxide (\%) and plasma catecholamine levels following methacholine inhalation in study 1 (hypoxia versus normoxia, $n=11$ ) and study 2 (hyperoxia versus normoxia, $n=14$ )

\begin{tabular}{|c|c|c|c|c|}
\hline \multirow{2}{*}{$\begin{array}{l}\text { Measurement after methacholine } \\
\text { inhalation }\end{array}$} & \multicolumn{2}{|l|}{ Study 1} & \multicolumn{2}{|l|}{ Study 2} \\
\hline & $\begin{array}{l}\text { Normoxia } \\
\text { study day }\end{array}$ & $\begin{array}{l}\text { Hypoxia } \\
\text { study day }\end{array}$ & $\begin{array}{l}\text { Normoxia } \\
\text { study day }\end{array}$ & $\begin{array}{l}\text { Hyperoxia } \\
\text { study day }\end{array}$ \\
\hline aths/min) & $15.0(1.6)$ & $14.0(2.0)$ & $14.0 \quad(1.0)$ & $15.0(1.1)$ \\
\hline End $t$ & $3.70(0.18)$ & $3.86(0$. & $3.94(0.18)$ & $3.87(0.22)$ \\
\hline Plasma noradrenaline $(\mathrm{nmol} / \mathrm{l})$ & $1.60(0.16)$ & $1.40(0.25)$ & $1.66(0.29)$ & $1.63(0.28)$ \\
\hline Plasma adrenaline $(\mathrm{nmol} / \mathrm{l})$ & $0.08(0.02)$ & $0.06(0.02)$ & $0.07(0.02)$ & $0.07(0.02)$ \\
\hline
\end{tabular}

No significant differences were found between study days in either study.

oxide or plasma catecholamine levels between study days in either study (table 3).

\section{Discussion}

We found that acute hypoxia $\left(\mathrm{FiO}_{2}\right.$ 0.15) potentiated methacholine induced bronchoconstriction in asthma whereas acute hyperoxia $\left(\mathrm{FiO}_{2}\right.$ 1.0) had no effect.

The changes in oxygen saturation we observed in both studies and the fall in heart rate $^{8-10}$ seen on the hyperoxic study day would suggest that our closed breathing circuit has achieved significant alterations in vascular oxygen tension. Both hypoxia and hyperoxia in vivo may cause a rise in minute ventilation and subsequent fall in end tidal carbon dioxide levels. ${ }^{8-10}$ Hypocapnia in vivo is associated with increased airway tone. ${ }^{11-14}$ We have shown no significant difference in percentage end tidal carbon dioxide levels between study days which suggests that an increase in airway tone due to hypocapnia has not influenced our results. Nebuliser output may be affected by the molecular weight of the gas used to drive the nebuliser. Before both studies the nebuliser output was calculated on two occasions for each study gas. In study 1 the nebuliser output for both air $\left(\mathrm{FiO}_{2}\right.$ 0.21) and the hypoxic gas mixture $\left(\mathrm{FiO}_{2} 0.15\right)$ was $0.13 \mathrm{ml} / \mathrm{min}$ at a flow rate of $7 \mathrm{l} / \mathrm{min}$ and in study 2 the output for air $\left(\mathrm{FiO}_{2}\right.$ 0.21) and hyperoxia $\left(\mathrm{FiO}_{2} 1.0\right)$ was
$0.12 \mathrm{ml} / \mathrm{min}$ at $61 / \mathrm{min}$. Circulating catecholamines have effects on airway smooth muscle tone. ${ }^{15}$ Any alteration in circulating levels of catecholamines due to changes in oxygen tension and inhalation of methacholine could potentially alter airway reactivity to methacholine. We have not, however, observed any significant differences in circulating catecholamine levels in either study.

Our double blind study has demonstrated an increase in airway reactivity to methacholine following acute hypoxia, in keeping with a previous single blind study reported by Denjean et $a l^{3}{ }^{3}$ Previous animal studies have suggested that the potentiation of methacholine induced bronchoconstriction by hypoxia is attenuated by prior surgical chemodenervation, ${ }^{16}$ suggesting that the effect is mediated via peripheral chemoreceptors. This does not, however, explain why potentiation of methacholine constriction by hypoxia in bovine bronchial rings ${ }^{1}$ is observed in vitro in the absence of circulating humoral factors and neural innervation. In our study we have been unable to detect an increase in airway tone following 10 minutes of hypoxia as one would expect if this effect occurred as a consequence of bronchoconstriction due to hypoxia alone. Other animal studies have shown that potentiation of histamine and carbachol induced bronchoconstriction in sheep is significantly reduced by both intravenous cromolyn sodium ${ }^{17}$ and FPL57231, ${ }^{18}$ a leukotriene receptor antagonist, suggesting that alveolar hypoxia may stimulate release of inflammatory mediators. Hypoxia may also act directly on smooth muscle cells, altering signal transduction pathways and causing smooth muscle contraction, or it may act on vagal nerve endings to stimulate neurotransmitter release and hence cause bronchoconstriction. These findings are likely to have clinical relevance as the level of hypoxia we have induced is compatible with those seen in patients admitted to hospital with acute severe exacerbations of 
asthma. It would appear therefore that hypoxia occurs, not only as a consequence of acute severe asthma, but it may also increase airway responsiveness to bronchoconstrictor stimuli.

We have not demonstrated attenuation of methacholine induced bronchoconstriction in humans by hyperoxia, in contrast to the findings of both the in vitro and in vivo animal studies. ${ }^{12}$ This difference may be explained by species variation between the studies or by hyperoxia in vivo affecting bronchomotor tone via neural or humoral pathways and hence counteracting any direct effect of hyperoxia alone on airway smooth muscle responsiveness. Our results support and extend those of Wollner et al. ${ }^{5}$ We have, however, also examined the potential influences of hypocapnia and circulating catecholamines on airway reactivity during hyperoxia and have also found that our patients show the typical cardiovascular and respiratory responses to hyperoxia. Our results differ from those of Inoue et $a l^{4}$ who found that hyperoxia attenuated methacholine induced bronchoconstriction in asthmatic subjects. However, they used an inspired oxygen concentration of $30 \%$ whereas we used $100 \%$. Six of their patients had arterial oxygen tensions below $10 \mathrm{kPa}$ in keeping with resting hypoxaemia and, since inspiring $30 \%$ oxygen relieves hypoxic bronchoconstriction, ${ }^{1920}$ this effect may have falsely influenced their results.

In conclusion, these results show that acute hypoxia potentiates methacholine induced bronchoconstriction in patients with stable asthma. They suggest that the administration of high concentrations of inspired oxygen to patients with acute exacerbations of asthma may not only improve gas exchange but may also reduce airway responsiveness to certain constrictor stimuli.

This study was supported by a grant from the British Lung Foundation. We also acknowledge the support of Mr Gordon Burnside of the Department of Medical Physics.
1 Clayton RA, Nally JE, Thomson NC, McGrath JC. The effect of oxygen tension on responses evoked by methacholine and bronchodilators in bovine isolated bronchial rings. Pulm Pharmacol 1996;9:123-8.

2 Vidruk EH, Sorkness RL. Histamine induced reflex tracheal constriction is attenuated by hyperoxia and exaggerated by hypoxia. Am Rev Respir Dis 1985;132:287-91.

3 Denjean A, Roux C, Herve P, Bonniot JP, Comoy E, Duroux $\mathrm{P}$, Gaultier C. Mild isocapnic hypoxia enhances the bronchial response to methacholine in asthmatic patients. Am Rev Respir Dis 1988;138:789-93.

4 Inoue $\mathrm{H}$, Inoue $\mathrm{C}$, Okayama $\mathrm{M}$, Sekizawa $\mathrm{K}$, Hida W, Takishima T. Breathing 30 per cent oxygen attenuates bronchial responsiveness to methacholine in asthmatic pronchial responsiveness to methach

5 Wollner A, Ben-Dov I, Bar-Yishay E. Effect of hyperoxia on bronchial response to inhaled methacholine. Allergy 1991;46:35-9.

6 Goldstein DS, Feuertein G, Izzo JL Jr, Kopin IJ, Keiser Hr. Validity and reliability of liquid chromotography with electrchemical detection for measuring plasma levels of norepinephrine and epinephrine in man. Life Sci 1981;28 467

7 Hills $M$, Armitage P. The two-period cross-over clinical trial. Br f Clin Pharmacol 1979;8:7-20.

8 Jennet $S$. Hypoxia and hyperoxia in man: immediate effects on ventilation and heart rate. $\mathrm{PhD}$ thesis, Glasgow, 1964

9 Watt JG, Dumke PR, Comroe Jr JH. Effects of inhalation of 100 per cent and 14 per cent oxygen upon respiration of unanesthetized dogs before and after chemorecepto denervation. Am f Physiol 1942;138:610-17.

10 Dripps RD, Comroe Jr JH. The effect of the inhalation of high and low oxygen concentration on respiration, pulse rate, ballistocardiogram and arterial oxygen saturation rate, ballistocardiogram and arterial oxygen saturation (oximeter)

11 Newhouse MT, Becklake MR, Macklem PT, McGregor M Effect of alterations in end-tidal $\mathrm{CO}_{2}$ tension on flow resistance. F Appl Physiol 1964;19:745-9.

12 O'Cain CF, Hensley MJ, McFadden ER, Ingram RH. Pattern and mechanism of airway response to hypocapnia in normal subjects. F Appl Physiol 1979;47:8-12.

13 Sterling GM. The mechanism of bronchoconstriction due to hypocapnia in man. Clin Sci 1968;34:277-85.

14 Elshout FJJ, Herwaarden CLA, Folgering HTHM. Effects of hypercapnia and hypocapnia on respiratory resistance in normal and asthmatic subjects. Thorax 1991;46:28-32.

15 Thomson NC, Dagg KD, Ramsay SG. Humoral control of airway tone. Thorax 1996;55:461-4.

16 Denjean A, Canet E, Praud JP, Gaultier CL, Bureau M. Hypoxia-induced bronchial responsiveness in awake sheep: role of carotid chemoreceptors. Respir Physiol 1991; 83:201-10.

17 Ahmed T, Marchette B. Hypoxia enhances nonspecific bronchial reactivity. Am Rev Respir Dis 1985;132:839-44.

18 D'Brot, Ahmed T. Hypoxia-induced enhancement of nonspecific bronchial reactivity: role of leukotrienes. $f \mathrm{Appl}$ specific bronchial reacti
Physiol 1988;65:194-9.

19 Libby DM, Briscoe WA, King TKC. Relief of hypoxia related bronchoconstriction by breathing 30 per cent oxygen. Am Rev Respir Dis 1981;123:171-5.

20 Astin TW. The relationships between arterial blood oxygen saturation, carbon dioxide tension, and $\mathrm{pH}$ and airway resistance during 30 per cent oxygen breathing in patients with chronic bronchitis with airway obstruction. Am Rev Respir Dis 1970;102:382-7. 